\title{
Coexistence of Obstructive Sleep Apnea and Superior Vena Cava Syndromes Due to Substernal Goitre in a Patient With Respiratory Failure:A Case Report
}

\author{
Mehtap Tunc ${ }^{1, *} ;$ Hilal Sazak ${ }^{1}$; Bulent Karlilar $^{1}$; Fatma Ulus $^{1}$; Irfan Tastepe $^{2}$ \\ ${ }^{1}$ Department of Anesthesiology and Reanimation, Ataturk Chest Disease and Thoracic Surgery Training and Research Hospital, Ankara, Turkey \\ ${ }^{2}$ Department of Thoracic Surgery, Gazi University Medical Faculty, Ankara, Turkey \\ *Corresponding Author: Mehtap Tunc, Department of Anesthesiology and Reanimation, Ataturk Chest Disease and Thoracic Surgery Training and Research Hospital, Ankara, Turkey. \\ Tel:+90-3123825582, Fax: +90-3124817783, E-mail: drmehtaptunc@yahoo.com
}

Received: February 21, 2014; Revised: September 7, 2014; Accepted: March 20, 2015

\begin{abstract}
Introduction: Substernal goiter may rarely cause superior vena cava syndrome (SVCS) owing to venous compression, and cause acute respiratory failure due to tracheal compression. Obstructive sleep apnea syndrome (OSAS) may rarely occur when there is a narrowing of upper airway by edema and vascular congestion resulting from SVCS.

Case Presentation: We presented the clinical course and treatment of acute respiratory failure (ARF) developed in a patient with SVCS and OSAS due to substernal goiter. After treatment of ARF with invasive mechanical ventilation, weaning and total thyroidectomy were successfully performed through collar incision and median sternotomy without complications.

Conclusions: Our case showed that if the respiratory failure occurred due to substernal goiter and SVCS, we would need to investigate the coexistence of OSAS and SVCS.
\end{abstract}

Keywords: Substernal Goiter; Superior Vena Cava Syndrome; Apneas, Sleep; Respiratory Failure

\section{Introduction}

Substernal goiter may be defined as any thyroid enlargement that has its greater mass inferior to the thoracic inlet (1). The most common symptoms are cervical mass, dyspnea, dysphagia, dysphonia, stridor, and hoarseness (1-3). Substernal goiters may rarely cause Superior Vena Cava Syndrome (SVCS) owing to venous compression, and Acute Respiratory Failure (ARF) due to tracheal compression (4-6).

OSAS (Obstructive Sleep Apnea Syndrome) is characterized by repetitive episodes of airflow cessation (apnea) due to upper airway collapse during sleep. The factors narrowing upper airway or causing its collapse increase the likelihood of OSAS (7). Rarely, OSAS may occur when there is a narrowing of upper airway by edema and vascular congestion resulting from $\operatorname{SVCS}(8,9)$.

We presented the clinical course and the treatment of ARF developed in a patient with SVCS due to substernal goiter. In our case, there was no apparent tracheal obstruction leading to ARF on admission.

Hence, based on his history, physical examination, determination of obesity as a risk factor, and findings of polysomnography, it was considered that ARF might have been complicated by the progression of OSAS due to SVCS.

\section{Case Presentation}

A 60-year-old male had the symptoms of dyspnea, orthopnea, swelling in hands and feet, and cyanosis in lips and tongue for two months. He was admitted to a healthcenter and diagnosed with SVCS due to substernal goiter. After 2 days, his condition deteriorated, and he was admitted to emergency department of our hospital. On physical examination, excessive edema and cyanosis in upper chest wall and head-neck area were found out. His neck was short and thick with restricted movements. As he had developed dyspnea and arrhythmia, he was transferred to surgical intensive care unit. According to medical records, he had unsatisfactory sleep quality, excessive daytime sleepiness, severe snoring, and sleep apnea since 2 months ago. His body mass index (BMI) was $39 \mathrm{~kg} / \mathrm{m}^{2}$, indicating obesity. Thyroid function tests revealed euthyroidism. His chest X-ray showed bilateral upper mediastinal enlargement and deviation of trachea (Figure 1). Thorax computerized tomography (CT) revealed the deviation of trachea without obstruction, and compression of superior vena cava by the right lobe of thyroid gland. Previous polysomnography findings were obtained. Apnea-hypopnea index (AHI) was calculated as 26.7 episodes/h and nocturnal oxygen desaturation was documented as 65\%. OSAS was diagnosed with the aid of polysomnography. 


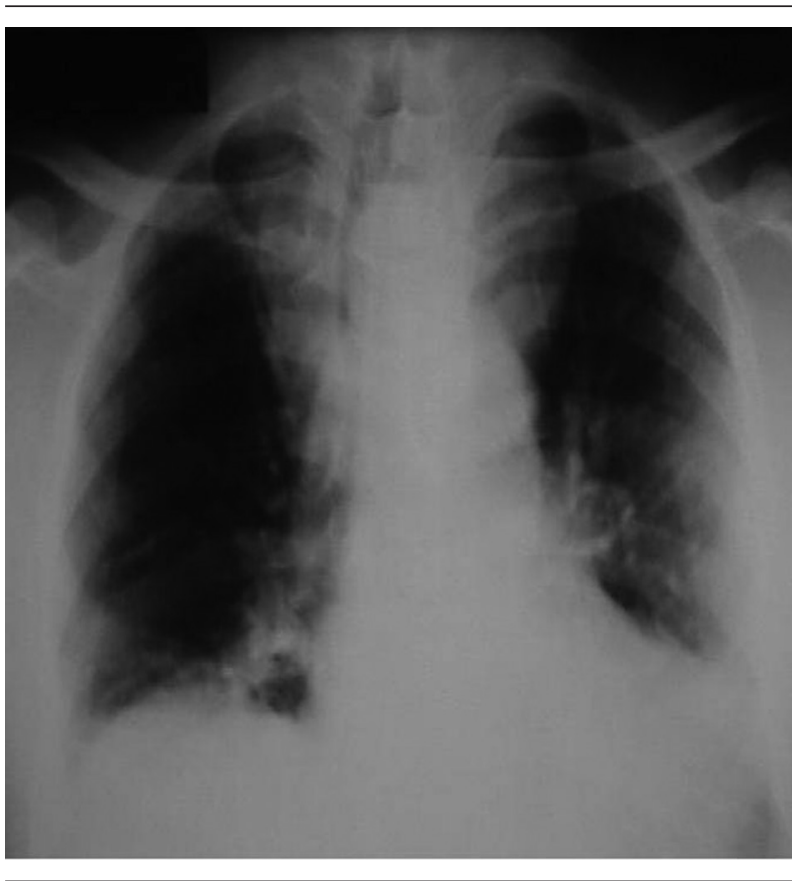

Figure 1. Chest X-ray Showing Bilateral Enlargement of Upper Mediastinal and Deviation of Trachea

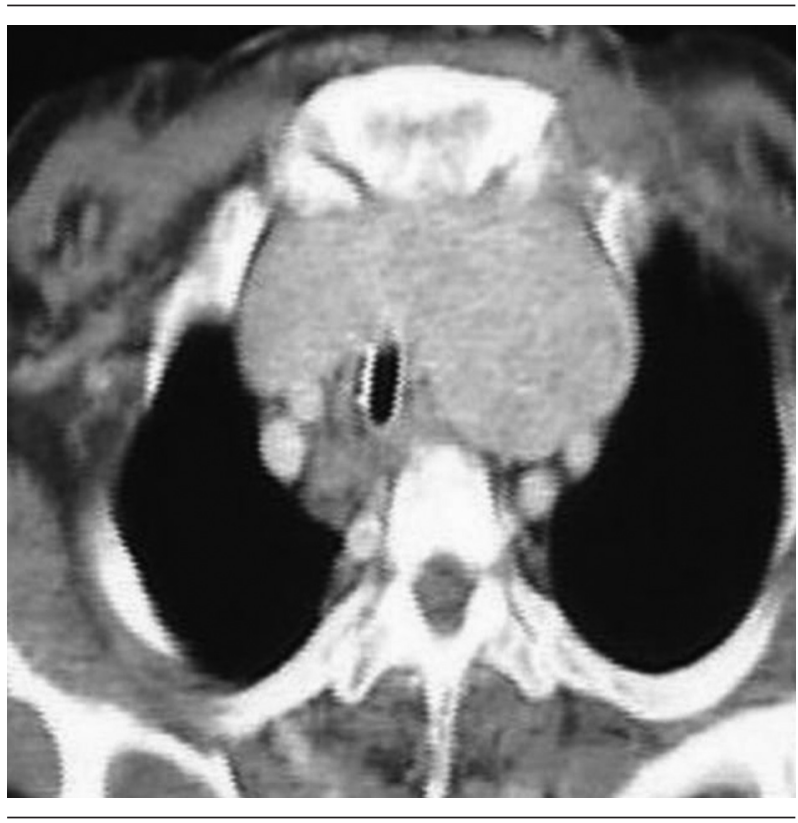

Figure 2. The Enlargement of Thyroid Gland, Compression of Trachea (After ICU and Before Operation)

An urgent endotracheal intubation and mechanical ventilation were planned because of severe respiratory acidosis and hypercapnia (pH: 7.192, $\mathrm{PaCO}_{2}: 145 \mathrm{mmHg}$ $\mathrm{PaO}_{2}: 60 \mathrm{mmHg}$ with $8 \mathrm{~L} / \mathrm{min}$ nasal oxygen supplement). Following preoxygenation with $100 \% \mathrm{O}_{2}$ via face mask, light anesthesia was induced with propofol, and laryngoscopy was applied without muscle relaxant. Spontaneous respiration was preserved after the administration of propofol. In the laryngoscopic assessment, Cormack and Lehane grade was considered as 4. The laryngeal Mask Airway (LMA) was placed promptly after failed endotracheal intubation. Mechanical ventilation was initiated through LMA and tracheostomy was performed uneventfully. The patient with SVCS was given antiedemal (steroid and diuretic), empiric antibiotic, and bronchodilator treatment in intensive care unit. Hence, his upper extremity and face-neck edema were reduced evidently. The steroid treatment was stopped, when nosocomial pneumonia was diagnosed on the 12th day. After the treatment of pneumonia, steroid treatment was restarted. The ventilatory mode was changed from synchronized intermittent mandatory ventilation (SIMV) to continuous positive airway pressure (CPAP) when arterial blood gas analysis revealed acceptable values ( $\mathrm{pH}$ : 7.494, $\mathrm{PaCO}_{2} 37.1 \mathrm{mmHg}$, $\mathrm{PaO}_{2} 64.9 \mathrm{mmHg}, \mathrm{HCO}_{3} 27.9$ using $\mathrm{FiO}_{2}$ 0.35) on the 35th day of mechanical ventilation. CPAP ventilation was applied for one week. Follow up T connector with oxygen supply was put on the tracheostomy cannula. Weaning was performed successfully on the 45th day.

Tracheal compression resulting from the enlargement of thyroid gland extending to substernal archus was detected in control CT after weaning (Figure 2). The case was referred to thoracic surgeon, and he decided to perform thyroidectomy. The patient lost weight rapidly and thyroid function test indicated hyperthyroidism, which was attributed to the radiopaque agent used for CT. As soon as the result of thyroid function test returned to normal range, total thyroidectomy was performed successfully through collar incision and median sternotomy in elective conditions. Histopathological examination revealed a benign multinodular goiter. He was recovered and discharged from the hospital on the 14th postoperative day.

\section{Discussion}

SVCS can occur by extrinsic venous compression of a primary lung or mediastinal neoplasm, mediastinal lymph node metastasis, a benign tumor, or intraluminal thrombosis (1-3). The substernal goiter may rarely cause a life threatening serious compression of the mediastinal vessels and respiratory tract despite its benign nature $(4-6,10)$. Intrathoracic goiter was detected in 28 of 4895 patients who were operated because of thyroid gland diseases, reported by Cichon et al. (6). SVCS was notified in only one of the patients with intrathoracic goiter. Substernal goiter and SVCS presented a difficult diagnostic and therapeutic challenge. The majority of SVCS patients have abnormal chest X-ray with signs of widening of mediastinum and pleural effusion. CT of the chest with contrast is a preferable method for diagnosis of SVCS today (11). SVCS was diagnosed with clinical findings, chest $\mathrm{X}$-ray, and CT in our patient.

Approximately $2 \%$ of patients undergoing thyroidectomy for substernal goiter will require sternotomy or tho- 
racotomy other than a standard collar incision (12). Thyroidectomy for substernal goiters should be performed by surgeons with a special interest and experience in thyroid surgery to ensure in minimizing the complications. Total thyroidectomy was performed successfully through collar incision and median sternotomy without complications in elective conditions in the present patient.

OSAS is characterized by repetitive episodes of airflow reduction (hypopnea) or cessation due to pharyngeal narrowing, leading to acute gas exchange abnormalities and sleep interruptions. The history should focus on breathing disturbances during sleep, unsatisfactory sleep quality, and daytime somnolence. Polysomnography in a sleep laboratory is the gold standard for confirming the diagnosis of OSAS (7). The apnea-hypopnea index can be instructive concerning prognosis and outcomes among critical patients in intensive care (13).

Few clinical cases have been reported about OSAS caused by SVCS. Fuyuno et al. (8) reported severe snoring at night and excessive daytime sleepiness in a SVCS patient with mediastinal tumor. Afterwards, they diagnosed OSAS with respiratory inductive plethysmography. They correlated the severity of snoring and oxygen desaturation during sleep with the progression of facial swelling. Ito et al. (9) treated a patient with SVCS caused by adenocarcinoma of the lung. His patient had severe snoring during sleep and daytime hypersomnolence. Then, they also diagnosed OSAS with respiratory inductive plethysmography. Yokoba et al. (14) showed that SVCS would exacerbate OSAS. The present case thought that SVCS aggravated the symptoms of OSAS.

The treatment options of SVCS include supportive steroid and diuretic therapy (which is temporarily), radiotherapy, and chemotherapy, and stent placement. In our patient, it was noticed that his upper extremity and face-neck edema reduced with steroid treatment. Previous clinical and polysomnographic findings suggested a relationship between SVCS and OSAS in our patient. OSAS may cause deterioration of respiratory dynamics and the quality of life when it develops secondary to SVCS.

Obesity is also a very strong predictor of OSAS, increasing the risk of apnea by 10 times. Weight loss of 10\% would result in reductions of apnea index by $26 \%$ (15). Because of thyrotoxicosis, our patient lost weight rapidly and his BMI reduced to $28 \mathrm{~kg} / \mathrm{m}^{2}$. Gutierrez et al. showed that 5 patients with multinodular goiter and OSAS relieved from OSAS after thyroidectomy (16). On the examination following the surgery, it was monitored that the predisposing factors disappeared and the symptoms were ameliorated.

We reported a case presenting with acute respiratory failure and SVCS due to substernal multinodular goiter. In the previous articles, the relationship between substernal goiter and OSAS was defined (16). OSAS can lead to ARF $(17,18)$. OSAS induced ARF has different the clinical and laboratory characteristics (18). Our case showed that if the respiratory failure occurred due to substernal goiter and SVCS, we should investigate the coexistence of OSAS and SVCS. In these complicated cases and prior to the major operation, with maintaining the elective conditions, the surgical treatment would be successful.

\section{Financial Disclosure}

The authors declared that there was no conflict of interests and the work was not a part of any commercial organization project.

\section{References}

1. Batori M, Chatelou E, Straniero A. Surgical treatment of retrosternal goiter. Eur Rev Med Pharmacol Sci. 2007;11(4):265-8.

2. Rodriguez JM, Hernandez Q, Pinero A, Ortiz S, Soria T, Ramirez P, et al. Substernal goiter: clinical experience of 72 cases. Ann Otol Rhinol Laryngol. 1999;108(5):501-4.

3. Netterville JL, Coleman SC, Smith JC, Smith MM, Day TA, Burkey BB. Management of substernal goiter. Laryngoscope. 1998;108(11 Pt1):1611-7.

4. Ríos Zambudio A, Rodríguez González JM, Carrasco Prats M, Piñero Madrona A, Soria Cogollos T, Parrilla Paricio P. Síndrome de vena cava superior por bocio multinodular. Rev Clin Esp. 2000;200(4):208-11.

5. McKellar DP, Verazin GT, Lim KM, Spiegel JC, Block BL. Superior vena cava syndrome and tracheal obstruction due to multinodular goiter. Head Neck.1994;16(1):72-4.

6. Cichon S, Barczynski M, Rogula T. [Intrathoracic goiter as a cause of superior vena cava syndrome]. Przegl Lek.1998;55(11):626-8.

7. Olson EJ, Moore WR, Morgenthaler TI, Gay PC, Staats BA. Obstructive sleep apnea-hypopnea syndrome. Mayo Clin Proc. 2003;78(12):1545-52.

8. Fuyuno G, Kobayashi R, Iga R, Nomori H, Kodera K, Morinaga S. [Obstructive sleep apnea syndrome associated with superior vena cava syndrome]. Nihon Kyobu Shikkan Gakkai Zasshi. 1995;33(3):322-6.

9. Ito M, Tanaka J, Kubota K, Sato H, Takahashi M, Tanaka H, et al [Obstructive sleep apnea syndrome in a patient with superior vena cava syndrome caused by lung cancer]. J Jpn Respir Soc. 2000;38(6):471-5.

10. Ket S, Ozbudak O, Ozdemir T, Dertsiz L. Acute respiratory failure and tracheal obstruction in patients with posterior giant mediastinal (intrathoracic) goiter. Interact Cardiovasc Thorac Surg. 2004;3(1):174-5.

11. Stevo D. Malignant superior vena cava syndrome: endovascular stent treatment-current status. J Palliative Care Med. 2012;2(1.2).

12. Hardy RG, Bliss RD, Lennard TW, Balasubramanian SP, Harrison BJ. Management of retrosternal goitres. Ann R Coll Surg Engl. 2009;91(1):8-11.

13. Gücyetmez B, Atalan HK. Apnea-hypopnea index use among intensive care patients: a case series. J Med Case Rep. 2014;8(1):181.

14. Yokoba M, Ishii N, Ichikawa T, Wada M, Mitsufuji H, Kubota M, et al. Association of Superior Vena Cava Syndrome with Sleep Apnea: Investigation Using an Impulse Oscillometry System. Int $J$ Clin Med.2012;3:270-5.

15. Salvador J, Iriarte J, Silva C, Gomez Ambrosi J, Diez Caballero A, Fruhbeck G. [The obstructive sleep apnoea syndrome in obesity: a conspirator in the shadow]. Rev Med Univ Navarra. 2004;48(2):55-62.

16. Gutierrez T, Leong AC, Pang L, Chevretton E, Jeannon JP, Simo R. Multinodular thyroid goitre causing obstructive sleep apnoea syndrome. J Laryngol Otol. 2012;126(2):190-5.

17. Sturani C, Galavotti V, Scarduelli C, Sella D, Rosa A, Cauzzi R, et al. Acute respiratory failure, due to severe obstructive sleep apnoea syndrome, managed with nasal positive pressure ventilation. Monaldi Arch Chest Dis. 1994;49(6):558-60.

18. Huang S, Deng W, Li M. [Clinical analysis of syndrome of obstructive sleep apnea (OSA) induced acute respiratory failure]. Zhonghua Jie He He Hu Xi Za Zhi.1998;21(9):544-6. 